UDC 94(94).04

Submitted: 09.10.2017

LBC 63.3(0)6

Accepted: 22.12.2017

\title{
THE COMMONWEALTH OF AUSTRALIA: DEVELOPMENT OF FOREIGN POLICY IN THE 1920s
}

\author{
Evgeniya V. Kashina \\ Pacific National University, Khabarovsk, Russian Federation
}

\begin{abstract}
The paper is devoted to the making of Australian foreign policy course in the third decade of the twentieth century. The author analyzes the degree of Australia's foreign policy dependence on Great Britain and explores the reasons for Australia's desire for diplomatic independence. The decisions of the Imperial conferences and the position of the Australian politicians on this issue are shown. The urgency of research is determined by the need to reveal the degree of independence in making foreign policy by the Australian government from the will of Great Britain in the 1920s. In the postwar period, there is a rapid growth of the national self-awareness of Australians. Since the post-war conferences, representatives of the Australian Union have increasingly come up with the requirements of "equality of dominions" and the right of an individual voice in dealing with foreign policy issues. Analysis of the Australian foreign policy shows the formation of an independent foreign policy line, which developed under conditions of gradual liberation from British influence. The specifics of this process make it possible to identify ways for the development of Australian diplomacy both in the region and within the British Commonwealth, as well as in the world area.

Key words: foreign policy of Australia, Australian Commonwealth, The British Empire, dominion, mother country (metropole), Asian-Pacific region, Imperial conferences.

Citation. Kashina E.V. The Commonwealth of Australia: Development of Foreign Policy in the 1920s. Vestnik Volgogradskogo gosudarstvennogo universiteta. Seriya 4, Istoriya. Regionovedenie. Mezhdunarodnye otnosheniya [Science Journal of Volgograd State University. History. Area Studies. International Relations], 2018, vol. 23, no. 2, pp. 157-165. (in Russian). DOI: https://doi.org/10.15688/jvolsu4.2018.2.13

УДК 94(94).04

Дата поступления статьи: 09.10.2017

ББК 63.3(0)6

Дата принятия статьи: 22.12.2017
\end{abstract}

\section{АВСТРАЛИЙСКИЙ СОЮЗ: \\ СТАНОВЛЕНИЕ ВНЕШНЕПОЛИТИЧЕСКОГО КУРСА В 1920-е ГОДЫ}

\author{
Евгения Владимировна Кашина \\ Тихоокеанский государственный университет, г. Хабаровск, Российская Федерация
}

\begin{abstract}
Аннотация. В статье рассматривается процесс формирования внешнеполитического курса Австралийского союза в третье десятилетие XX века. Анализируется степень внешнеполитической зависимости Австралии от Великобритании. Раскрываются причины стремления Австралии к дипломатической самостоятельности. Анализируются решения Имперских конференций и позиции австралийских политиков по данному вопросу. Актуальность изучения проблемы определяется необходимостью выявить степень независимости в принятии внешнеполитических решений правительством Мельбурна от воли Великобритании в 1920-е годы. В послевоенное время происходит быстрый рост национального самосознания австралийцев. Начиная с послевоенных конференций, представители Австралийского союза все чаще выступали с требованиями «равенства доминионов» и права индивидуального голоса при решении внешнеполитических вопросов. Рассмотрение внешнеполитического курса Австралии показывает формирование самостоятельной внешнеполитической линии, которая развивалась в условиях постепенного освобождения от британского влияния. Особенности этого процесса позволяют определить возможные пути развития австралийской дипломатии как в регионе, так и в рамках Британского содружества, а также на мировой арене.
\end{abstract}


Ключевые слова: внешняя политика Австралии, Австралийский союз, Британская империя, доминион, метрополия, Азиатско-Тихоокеанский регион, Имперские конференции.

Цитирование. Кашина Е. В. Австралийский союз: становление внешнеполитического курса в 1920-е гг. // Вестник Волгоградского государственного университета. Серия 4, История. Регионоведение. Международные отношения. - 2018. - Т. 23, № 2. - C. 157-165. - DOI: https://doi.org/10.15688/jvolsu4.2018.2.13

Путь Австралии к независимости ускорился после провозглашения федерации в 1901 году. Первые шаги к обретению самостоятельности проявились во внутренней политике и экономической сфере еще до Первой мировой войны, но свою внешнюю политику ей постоянно приходилось согласовывать с метрополией, так как юридически Австралия являлась частью Британской империи. Связи с Лондоном по-прежнему были очень тесными и оказали глубокое влияние на внешнеполитический курс Австралии в межвоенный период.

Становлению послевоенного (1920-е гг.) внешнеполитического курса Австралийского союза в современной историографии уделяется мало внимания. В отечественной и зарубежной историографии в основном делается акщент на формировании самостоятельной внутренней политики и экономической самостоятельности британских доминионов. Это обусловлено тем, что среди историков общепризнанным является тезис об абсолютной зависимости внешнеполитического курса доминионов от метрополии вплоть до подписания Вестминстерского статута 1931 года. Поэтому большинство исследований лишь освещают факт принятия данного статута и его основные положения, не останавливаясь на тех глубинных процессах, которые привели к его утверждению.

Особенности внешнеполитического курса Австралии в 1920-е гг. заключались в нежелании втянуть себя в очередной конфликт, но при этом он находился в сильной зависимости от британской имперской политики. Каждое австралийского правительство настаивало на том, чтобы Великобритания не пренебрегала австралийскими интересами в Тихом океане. В 1920-е гг. австралийская внешняя политика была нацелена на сохранение мира в регионе и обеспечение обороноспособности на случай новой войны. Интересы Австралии в Лиге Наций не были достаточно защищены, в отличие от интересов Великобритании. Несмотря на формальное участие в послевоенных конференциях, Австралийский союз так и не получил права индивидуального голоса в подписании международных договоров. Версальский мирный договор с Германией был подписан от имени Британской империи, а затем отдельно представителями Канады, Австралии, Южной Африки и Новой Зеландии. Процедура подписания документа отражала неопределенность статуса доминионов. Вместо того, чтобы каждый доминион был указан в алфавитном порядке наряду с другими странами, сначала была упомянута Британская империя, а затем следовали имена и подписи представителей доминионов [21, p. 408]. Благодаря активной защите национальных интересов в Версале австралийским премьер-министром Уильямом Хьюзом Австралия получила мандат класса «С» на управление германской Новой Гвинеей и право на репарации от Германии, а также добилась отказа от принципа «равенства рас», который Япония пыталась включить в устав Лиги Наций [14, p. 151]. Несмотря на то что, Австралийский союз расширил свою сферу влияния в юго-западной части Тихого океана и сумел активно отстаивать свои интересы на Парижской конференции, большинство австралийцев еще не мыслили себя вне Империи. «Без империи, - говорил У. Хьюз, - нас будет вращать как пробку в бурном потоке мировой политики» (цит. по: [4, с. 122-123]).

После Первой мировой войны США и Япония усилили свои позиции в Азиатско-Тихоокеанском регионе. Вплоть до 1921 г. сохранялся англо-японский союз (1902 г.), под прикрытием которого Япония усилила свою экспансию на Тихом океане. Во время Первой мировой войны японские войска захватили ряд германских колониальных владений и готовили планомерное наступление на Китай. По итогам войны Япония получила контроль над ними к северу от экватора, а также право на оккупацию Шаньдуна. Передел территорий происходил при согласии Лондона, что больше всего настораживало правительство Мельбурна. Япония оказывалась потенциальным соперником Австралии на Тихом океане. Бо- 
лее того, одним из решений Вашингтонской морской конференции 1922 г. был отказ США от укрепления своих военных баз (Филиппины, Гуам) в акватории Тихого океана. Данное решение в определенной степени развязывало руки японскому флоту и предоставляло Японии стратегическую инициативу в регионе [5, с. 200]. В таких условиях Австралии были необходимы гарантии защиты и военной помощи со стороны Великобритании.

Основной задачей имперской конференции 1921 г. являлась организация единой международной политики Великобритании и ее доминионов, в частности отношения с Соединенными Штатами и Японией. Наиболее актуальным вопросом конференции был вопрос о целесообразности возобновления англо-японского альянса, который должен был истечь в 1921 г. Премьер-министр Австралии Уильям Хьюз и премьер-министр Новой Зеландии Билл Мэсси решительно высказались за его возобновление. Они не хотели, чтобы их страны были захвачены войной между США и Японией. Австралийские представители противопоставили щедрую помощь, оказанную Японией во время Первой мировой войны, сдержанной позиции США в поддержке своего британского союзника. Как объявил Хьюз, «Британская империя должна иметь надежного друга в Тихом океане». Премьер-министр Канады Артур Мейгхен выступил против, на том основании, что альянс отрицательно повлияет на отношения с Соединенными Штатами, от которых зависит безопасность Канады [13, p. 13-19]. В результате решение о возобновлении договора с Японией не было принято, и он утратил силу по истечении сроков. Широко распространено мнение, что «Япония не начнет крупномасштабную агрессию, до тех пор, пока западные державы в значительной степени не увязнут в Европе» (см.: [2]). Поэтому внешняя политика Австралии в отношении Великобритании была направлена на отвлечение метрополии от полного погружения в европейские проблемы. Австралийскому союзу нужна была защита в АТР, которую на данном этапе могла обеспечить только Великобритания.

В своей речи по поводу военно-морских сил Австралии и ее положения в АТР премьер Хьюз четко расставил приоритеты: «Мы дол- жны обладать такими военно-морскими силами и обороной, которые в полной мере обеспечат нашу безопасность. Естественно, главный вопрос, какое количество военно-морских сил необходимо для обеспечения нашей безопасности в АТР, в условиях послевоенного сокращения вооружений». Война и строительство Панамского канала переместили арену внешнеполитических конфликтов со Средиземноморья и Атлантики в Тихий океан: «именно здесь в будущем развернется великая драма. Американский флот сейчас находится в этих водах. Мир в Тихом океане означает мир для Империи и для всего мира. Необходимо соглашение между тремя морскими державами или, в худшем случае, между двумя, тогда увеличатся гарантии защиты Британской империи в Тихом океане. Положение Империи всегда определялось ее морской силой. И Австралия, во что бы то ни было, должна обладать достойным Империи военно-морским флотом» [13, p. 21] (здесь и ниже - перевод наш. $-E . K$.). Таким образом, Билли Хьюз начинает рассматривать Тихоокеанский регион как арену будущих мировых событий. Очевидно, что Австралия стремилась найти в АТР сильных союзников. Более того, растущий внешний долг толкал ее на сближение с США. Отсюда поддержка неудачных попыток 1921 г. заключить Трехстороннее соглашение (США - Австралия Великобритания). Изоляционизм Вашингтона на время создал препятствия для заключения данного соглашения. Правительство У. Гардинга с 1921 г. отказалось от «вильсоновской» позиции тотального вмешательства в международные дела и взяло курс на сдержанный изоляционизм. Он заключался в отказе от вступления в какие-либо международные договорные обязательства при сохранении американской торгово-экономической экспансии [17, p. 227-232]. Великобритания также не стремилась к союзу с США из-за противоречий, проявившихся на Парижской конференции [22, p. 190]. В межвоенные годы Великобритания уступает США не только финансовое лидерство, но и военно-морское превосходство. Нежелание Лондона заключать договор объяснялось еще и англо-американским соперничеством в Тихом океане. На Вашингтонской конференции 1922 г. Великобритания, не восстановившаяся после войны, была вынуждена согла- 
ситься на принцип равенства с США в военноморских силах. Теперь для своих ВМФ она уже довольствовалась не принципом равенства двум флотам крупнейших держав, а всего одному флоту [18, p. 260-261]. Таким образом, попытки австралийского правительства найти в лице США внешнеполитическую защиту не удались. Вместе с тем двустороннее австрало-американское соглашение было невозможно в связи с отсутствием у Австралийского союза права внешнеполитической инициативы. Необходимо было согласие Лондона, которого он не предоставил в связи с вышеперечисленными причинами. Не найдя сильных союзников в ближайшем геополитическом окружении, Австралия снова возвращается в лоно бывшей метрополии.

Сама Великобритания неоднозначно относилась к статусу своих доминионов. С одной стороны, она поддерживала право отдельного голоса, с другой - британское правительство утверждало, что международное право не применяется к отношениям между частями Британской империи. Великобритания отказалась предоставить доминионам право самостоятельно заключать международные соглашения. Австралийскую делегацию в Лиге Наций обычно возглавлял премьер-министр Австралийского союза [15, p. 280]. Доклад премьер-министра на каждой сессии Лиги Наций обычно обсуждался в парламенте Австралии. Это позволяло лучше обсудить внешнюю политику и поведение австралийских представителей в Лиге Наций. В Международной организации труда (МОТ) австралийские делегаты не всегда поддерживали позицию Великобритании. Однако в ходе прений в парламенте Содружества в 1929 г. было высказано мнение о том, что все части Империи должны голосовать единым блоком в МOT. Бывший делегат от МОТ Джон Бисли (Рабочая партия Австралии) объяснил эту позицию следующим образом: «Перед тем как британская делегация отправится из Лондона в Женеву, проводится конференция, на которую приглашен австралийский делегат. Рассматриваются вопросы, которые будут обсуждаться на основной конференции МОТ. Представители Австралии и других доминионов должны заранее обсудить все актуальные вопросы и к приезду британской делегации прийти к комп- ромиссу, чтобы на основной конференции действовать единым блоком, в соответствии с пожеланиями британского правительства» [9, p. 1751-1753]. Таким образом, самостоятельность и независимость Австралии в международных отношениях не была реальной. Все действия требовали согласования с бывшей метрополией.

Такая неопределенность относительно степени независимости Австралии на международной арене сохранялась в 1920-е годы. Основные вопросы внешней политики бывшая метрополия оставила за собой, предоставив Австралии свободу в решении второстепенных проблем. Британская империя с начала $\mathrm{XX}$ в. находилась в состоянии ослабления внутриимперских связей с доминионами. Поэтому Великобритания всячески пыталась препятствовать снижению международного авторитета Империи за счет подавления самостоятельности доминионов. В послевоенные годы Британии пришлось изменить свое отношение к доминионам. На заседании палаты общин в 1924 г. Стэнли Болдуин (лидер партии консерваторов Англии) отметил: «Империя простирается почти непрерывно от Сингапура до Кейптауна. Нехватка транспортных сообщений и другие трудности всегда будут источником неприятностей, и, прежде всего, сейчас существует проблема больших расходов, чем когда-либо в прошлом, и все меньше средств для ее решения. Например, Австралия глубоко заинтересована в гарантиях безопасности на Тихом океане, которые затрагивают не только флот и авиацию, но и всю армию. Эмиграция увеличится в ближайшем будущем, и власть Великобритании будет в значительной степени рассеиваться в доминионах. Следовательно, необходима сплоченность Империи с ее доминионами. Это лишь некоторые из причин для выдвижения необходимости координации между частями Империи» [7, р. 2154-2165].

Внешнеполитическая зависимость доминионов от Великобритании, проведение всех решений через английский парламент, отчетность во всех иностранных контактах, а также принцип совместной ответственности приводили к негативным последствиям. Например, инцидент в Чанаке ${ }^{1}$ (сентябрь 1922 г.), который мог развязать непопулярную англо- 
турецкую войну. Чанакский кризис и возможность очередной войны вызвали раскол в английском парламенте, а призывы премьер-министра Великобритании Дэвида Ллойда Джорджа к войне окончательно подорвали позиции либералов. Более того, все внешнеполитическиерешения в этом конфликте английский парламент принимал без консультаций с доминионами. В ответ на это Канада открыто отказалась поддержать Англию в данном конфликте. Это было первое заявление одного из доминионов о дипломатической независимости от Лондона. Истэблишмент Австралии публично не осудил позицию Ллойда Джорджа, но при этом и не поддержал. Таким образом, крайне остро встает вопрос о роли доминионов во внешнеполитических кампаниях Великобритании. Постепенно идет процесс разрушения имперских связей между доминионами и метрополией.

Зарождающаяся независимость австралийской внешней политики практически исчезла, когда Стэнли Брюс ${ }^{2}$ (занимал пост до 1929 г.) заменил Хьюза на посту премьер-министра в 1923 году. Он возглавлял коалиционное правительство, состоявшее из представителей двух наиболее влиятельных партий в 1920-е гг:: Националистической и Аграрной партии Австралии. Как отмечает Мейсон, новый премьер «глубоко уважал и верил в британскую систему» внешней политики: «Австралия вновь была готова разрешить Великобритании направить образец своей международной политики» $[19$, p. 177]. С другой стороны, Брюс признавал возможные опасности «дрейфа» Австралии в сторону сепаратизма. Он делал все возможное, чтобы обеспечить некоторую координацию имперской политики с 1923 по 1929 год. В действующем составе министерства иностранных дел Великобритании многиеполитики придерживались принципа «большой координации», то есть принципа согласия и взаимоподдержки между доминионами и Лондоном. Основная идея кабинета Брюса - участие Австралии в формировании британской внешней политики. Более того, предполагалось увеличение преференций в товарном обороте с Британией, а также максимальное использование английского капитала и австралийской рабочей силы для стимулирования австралийской экономики [6, с. 96].
В 1925 г. было создано Управление по делам доминионов, но до 1940 г. это ведомство действовало под контролем со стороны высшего колониального секретаря. Несмотря на значительную дипломатическую деятельность в годы премьерства Брюса, к концу его полномочий остались два нерешенных вопроса в имперских отношениях - вопрос равноправия британцев и жителей доминионов, а также международный статус последних.

В 1920-е гг. имперские конференции стали основным средством изменения статуса Австралии в структуре Британской империи.

Повестка дня Имперской конференции 1923 г. обсуждалась заранее в австралийском парламенте. Опыт Первой мировой войны в значительной степени повлиял на дискуссию. Премьер-министр Брюс заявил Палате представителей, что «если одна из частей Империи вовлечена в войну, задействована вся Империя». Также он отметил, что «если войны возникают из-за конфликтов во внешнеполитической сфере и, как показала история, Австралия неизбежно участвует во всех кампаниях Британии, тогда очевидно, что Австралия должна настаивать на том, чтобы иметь надлежащий голос в разработке этой внешней политики». Но при этом «если доминионы без консультаций с другими доминионами или с Великобританией заключат договоры от своего имени, которые при определенных обстоятельствах могли бы вовлечь Империю в войну, то такие действия будут крайне недопустимыми» [8, p. 1478-1481]. Необходимо отметить, что Австралия была более сдержанна в стремлении к внешнеполитической самостоятельности, чем Канада и ЮАР. Подобная сдержанность была обусловлена тем, что большая часть австралийского экспорта была ориентирована на британский рынок. Более того, сохранялись исторически сложившиеся тесные культурные связи с метрополией на основе общей английской ментальности. Географическая удаленность Австралии и Новой Зеландии от метрополии превращала эти страны в незащищенные британские анклавы в акватории Тихого океана и создавала трудности в прямом взаимодействии с Лондоном. Фактически, на конференции Стэнли Брюс поддержал позицию Великобритании, которая заключалась в наделении Имперских конференций правом выработки общеимперс- 
кого внешнеполитического курса, который был бы равно обязательным для всех частей Империи. Против выступили премьер-министр Канады Уильям Кинг и премьер-министр Южной Африки Дж.Б. Герцог. Они утверждали, что признание обязательности решений конференции в разработке внешней политики доминионов будет посягать на их автономию, а внешняя политика каждого доминиона должна определяться его парламентом [20, p. 204]. Великобритания признавала сложность любой попытки общей имперской инициативы и трудности, присущие кооперативному началу в Империи. Но страх потерять контроль над внешней политикой доминионов, многие из которых являлись геополитически и экономически выгодными для Британии территориями, привел к тому, что данная позиция «политического страха» была отражена в окончательных резолюциях Имперской конференции 1923 года. Конференция признала за Австралией и другими доминионами право заключать договоры с иностранными державами, а также определила обязанность по информированию других доминионов и метрополии в своих намерениях. Вместе с тем предварительное рассмотрение любой потенциальной опасности для Империи было обязательным. Двусторонние договоры, которые налагали обязательства только на одну часть Империи, могли быть подписаны представителем той части Империи. Договоры, согласованные на международных конференциях, подлежат подписанию представителями всех правительств Империи, представленных на Конференции. Также было отмечено, что «каждое правительство должно решить, требуется ли утверждение парламентом какого-либо договора, прежде он пройдет ратификацию в правительстве» [20, p. 206]. Таким образом, право доминионов самостоятельно заключать договоры с иностранными государствами было утверждено, но только при согласии Лондона и через информирование об этом всех остальных доминионов. Эти тонкости международного права не были простым изменением правил. Речь шла о постепенном достижении доминионами независимого от метрополии статуса, выраженном в дальнейшем пересмотре конституционного характера внутриимперских отношений [3, с. 31].
На Имперской конференции 1926 г. эти руководящие принципы по заключению международных договоров были пересмотрены и усилены в так называемой Декларации Бальфура, названной в честь председателя комитета по внутриимперским отношениям, лорда Артура Бальфура. Более того, декларация признала доминионы «автономными сообществами в Британской империи, равными по статусу, никаким образом не подчиняющимися друг другу в любом аспекте их внутренних или внешних дел, хотя они объединены общей преданностью короне и свободно связаны как члены Британского Содружества Наций». Оставаясь верными имперской политике, представители Британии настояли на сохранении «системы связи и консультаций» в период между конференциями $[16$, p. $10 ; 3-5]$. Так как Имперские конференции не обладали правом законодательной инициативы, тем более в изменении конституционных основ британских доминионов, ряд решений имел лишь декларативный характер. Например, доминионы не получили права выхода из Империи, и приоритетный голос во внешней политике оставался у Лондона. На этой конференции Австралия не столь активно отстаивала позицию независимости, она все еще была не готова пойти на окончательный разрыв с метрополией и нуждалась в ее военной силе и финансах [1, с. 14-15].

Краткий отчет о работе Имперской конференции 1926 г. был представлен и обсужден в парламенте Содружества 3 марта 1927 г. $[10$, p. $62-80]$. Некоторые члены считали, что Конференция просто признала существующую независимость Австралии. Другие отметили, что Имперские конференции не имеют конституционного статуса и законодательных полномочий и поэтому не могут освободить Австралию от юридических ограничений, например таких, как Акт о легитимности колониальных законов ${ }^{3}$.

Однако Конференция 1926 г. не проигнорировала тот факт, что законодательные изменения могут потребоваться для принятия принципа о равенстве статуса доминионов, для изменения их конституционного статуса. Соответственно, на заседании было принято решение создать технический комитет для рассмотрения данного вопроса. Комитет заседал в Лондоне с октября по декабрь 1929 года. Австра- 
лийским представителем был профессор права Мельбурнского университета Харрисон Мур. Доклад Комитета был представлен в парламент Австралийского союза 25 июня 1930 года. В докладе декларировалось следующее:

- устранение конституционных положений, касающихся отмены каких-либо законов, и вопрос о необходимости королевского одобрения передаются на рассмотрение властям Австралии;

- Парламент Соединенного Королевства законодательно постановляет с согласия доминионов заявить, что парламенты доминионов имеют полное право принимать законы по экстерриториальным вопросам;

- на основе принципа равенства, принятого на Имперской конференции 1926 г., Акт о легитимности колониальных законов отменяется в отношении доминионов;

- парламент Соединенного Королевства не имеет права принимать законы в отношении доминионов без их согласия;

- установить конституционную конвенцию о том, что любые изменения в престолонаследии требуют согласия доминионов [11, p. 3205-3208].

Комитет также рассмотрел вопрос о гражданстве и о создании отдельного закона о гражданстве, но не мог решить проблему.

Дискуссия по докладу Комитета показала, что Австралия по-прежнему избегала формализации своих отношений с Соединенным Королевством. Например, Чарльз Латхам (заместитель премьер-министра Западной Австралии от Аграрной партии) критиковал отчет, предупреждая, что расширение полномочий законодателей лишит авторитета политиков. Он считал, что «Австралия должна гораздо больше заботиться о сохранении и укреплении единства Британской империи, чем бороться за какую-то формальную независимость, которая не была бы реальной вне Империи».

Бывший премьер-министр Хьюз заявлял: «Я полностью против этой бесполезной, но опасной попытки изложить в письменной форме отношения, существующие между различными частями Империи». Делегат от рабочей партии Ричард Крауч утверждал, что «законотворцы уже низложили политиков, когда Высший суд признал части Навигационного акта недействительными из-за применения Положения о легитимности колониальных законов». Именно поэтому, на его взгляд, принципу «равенства доминионов» 1926 г., необходимо законодательное оформление [12, p. 5143].

Очевидно, что на практике старые законы колониального периода все еще действовали на территории Империи и препятствовали развитию австралийского законодательства. Следовало отменить такие устаревшие акты, как «Акт о верховенстве колониальных законов», так как данный закон составлялся применительно к колониям, но подобным статусом в 1920-е гг. Австралийский союз уже не обладал.

Таким образом, в 1929 г. были составлены основные положения о равенстве доминионов и изменении их конституционного статуса. Декларировалась независимость доминионов в разработке собственного внешнеполитического курса. Но без законодательного оформления данные решения не могли вступить в силу.

В 1920-е гг. не произошло кардинальных изменений в обретении Австралией внешнеполитической самостоятельности, но именно в этот период наиболее активно складываются предпосылки к данному процессу. В Австралии происходит переоценка международных приоритетов, выражавшаяся в борьбе между традиционным осознанием себя частью британской нации и резким подъемом национального самосознания после войны. Несмотря на то, что в третьем десятилетии XX в. преобладала первая установка, в парламентских дебатах очень часто слышались призывы к усилению Австралии в Тихом океане, а также предложения возможных внешнеполитических союзов. Представители Австралии принимают активное участие в послевоенных международных и Имперских конференциях. Именно в 1920-е гг. происходила подготовка и обсуждение будущего законодательного оформления внешнеполитической независимости Австралийского союза и других доминионов, утвержденного Вестминстерским статутом 1931 года.

\section{ПРИМЕЧАНИЯ}

1 Чанакский кризис 1922 г.: конфликт между Великобританией и Турцией, вызванный попытка- 
ми турецкой армии вернуть оккупированные союзниками территории Турции. Выбив у греческой армии Измир, турецкие войска вошли в нейтральную зону черноморских проливов. Британское правительство вынесло Турции ультиматум с угрозой войны от имени Британии и ее доминионов в связи с нарушением Турцией статей Севрского договора. Благодаря господству антивоенных настроений среди союзников Англии и среди большинства английских министров войны удалось избежать. Турции была предоставлена Восточная Фракия взамен на вывод турецких войск из нейтральной зоны. Окончательно решение проблемы на законодательном уровне произошло в ходе Лозаннской конференции 1923 г.

2 Стэнли Мелборн Брюс (1883-1967 гг.): премьер-министр Австралии с 1923 по 1929 г. Получил юридическое образование. Участвовал в Первой мировой войне. Награжден британским военным крестом. После войны - член националистической партии Австралии. В 1918 г. избран в парламент. В 1921 г. назначен министром финансов. Заключив союз с лидером аграрной партии Эрлом Пейджом, с 1923 г. получает должность премьер-министра. Также исполнял обязанности министра иностранных дел. В своей политике выражал интересы пробританской национальной буржуазии и военных.

3 Акт о легитимности колониальных законов признавал недействительными законы колоний, противоречащие правовым актам Вестминстерского парламента. Он также предусматривал, что колонии не имеют права вносить поправки в свою конституцию, кроме как в предписанной законом форме (напр., через референдум).

\section{СПИСОК ЛИТЕРАТУРЫ}

1. Зимулина, Л. А. Борьба английских доминионов за расширение политических прав в 19231929 годах : автореф. дис. ... канд. ист. наук / Зимулина Л. А. - М., 1967. - 18 c.

2. Кошкин, А. А. Первая мировая война и Восток / А. А. Кошкин // Новая и новейшая история. - 1998. - № 5. - С. 40-50.

3. Мартынов, А. И. Австралия в международных отношениях XX в. / А. И.Мартынов, О. К. Русакова. - М. : Мысль, 1978. - 352 с.

4. Массов, А. Я. Участие Австралии в работе Парижской мирной конференции 1919 г. / А. Я. Массов // Великая война 1914-1918 : Альманах Российской ассоциации историков Первой мировой войны. М. : Квадрига, 2011.- № 1. -С. 116-123.

5. Сборник договоров и других документов по истории международных отношений на Даль- нем Востоке / под ред. Э. Д. Гримм. - М. : Изд-во Ин-та востоковедения им. Нариманова, 1927. $218 \mathrm{c}$.

6. Скоробогатых, Н. С. История Австралии. ХХ век / Н. С. Скоробогатых. - М. : ИВ РАН, 2015. $452 \mathrm{c}$.

7. Commons Sitting of 18 June 1924. Imperial preference : Official Hansard, 1924. - Series 5, vol. 174. - P. 2153-2270

8. Commonwealth. House of Representatives. Parliamentary Debates of 24 July 1923 : Official Hansard, 1923. - Vol. 104. - P. 1466-1516.

9. Commonwealth. House of Representatives. Parliamentary Debates of 22 March 1929 : Official Hansard, 1929. - Vol. 120. - P. 1726-1763.

10. Commonwealth. House of Representatives. Parliamentary Debates of 3 March 1927 : Official Hansard, 1927. - Vol. 115. - P. 56-110.

11. Commonwealth. House of Representatives. Parliamentary Debates of 25 June 1930 : Official Hansard, 1930. - Vol. 125. - P. 3199-3265.

12. Commonwealth. House of Representatives. Parliamentary Debates of 1 August 1930 : Official Hansard, 1930. - Vol. 126. - P. 5127-5163.

13. Conference of prime ministers and representatives of the United Kingdom, the Dominions, and India, held in june, july, and august, 1921. Session I-II. - London, 1921. - 68 p.

14. Evatt, H. The Royal Prerogative / H. Evatt. Sydney: Law Book Co., 1987. - 425 p.

15. Harvey, H. Consultation and Co-Operation in the Commonwealth / H. Harvey. - Oxford University Press, 1952. $-411 \mathrm{p}$.

16. Imperial Conference 1926. Summary of proceedings. - Dublin, 1926. $-62 \mathrm{p}$.

17. Jonas, M. Isolationism / M. Jonas. - New York: Encyclopedia of American foreign policy, 1978. Vol. 2. -315 p.

18. Kennedy, P. The Realities behind diplomacy: Background influences on British external policy (1865-1980) / P. Kennedy. - London : Fontana press, 1989. $-416 \mathrm{p}$.

19. Mason, K. J. Experience of Nationhood: Australia and the World Since 1900 / K. J. Mason. Sydney: McGraw Hill, 1985. - 450 p.

20. McIntyre, P. The Strange Death of Dominion Status / P. McIntyre // Journal of Imperial and Commonwealth History. - 1999. - Vol. 27, № 2. P. 193-212.

21. Meaney, N. A history of Australian defence and foreign policy 1901-1923 / N. Meaney. - Sydney : Sydney University Press, 2009. - Vol. 2. -450 p.

22. Parsons, E. Wilsonian diplomacy: AlliedAmer.rivalries in war and peace / E. Parsons. St. Louis : Forum press, 1978. -213 p. 


\section{REFERENCES}

1. Zimulina L.A. Borba angliyskikh dominionov za rasshirenie politicheskikh prav $v$ 1923-1929 godakh: avtoref. dis. ... kand. ist. nauk [The British Dominions' Struggle for the Expansion of Political Rights in 1923-1929]. Moscow, 1967. 18 p.

2. Koshkin A.A. Pervaya mirovaya voyna i Vostok [The First World War and the East]. Novaya $i$ noveyshaya istoriya [Modern and Contemporary History], 1998, vol. 5, pp. 40-50

3. Martynov A.I., Rusakova O.K. Avstraliya v mezhdunarodnykh otnosheniyakh $X X v$. [Australia in International Relations of the $20^{\text {th }}$ Century]. Moscow, Mysl Publ., 1978. 352 p.

4. Massov A.Ya. Uchastie Avstralii v rabote Parizhskoy mirnoy konferentsii 1919 g. [Australia's Participation in the Paris Peace Conference]. Velikaya voyna 1914-1918. Almanakh Rossiyskoy assotsiatsii istorikov Pervoy mirovoy voyny [Great War of 19141918. Almanac of the Russian Association of Historians of the First World War]. Moscow, Kvadriga Publ., 2011, no. 1, pp.116-123.

5. Grimm E.D., ed. Sbornik dogovorov $i$ drugikh dokumentov po istorii mezhdunarodnykh otnosheniy na Dalnem Vostoke (1842-1925) [A Collection of Treaties and Other Documents about the History of International Relations in the Far East]. Moscow, Institut vostokovedeniya Publ., 1927. $218 \mathrm{p}$.

6. Skorobogatykh N.S. Istoriya Avstralii. XXvek [Australia's History. The $20^{\text {th }} \mathrm{c}$.]. Moscow, IV RAN Publ., 2015. 452 p.

7. Commons Sitting of 18 June 1924. Imperial preference. Official Hansard, 1929. Series 5, vol. 174, pp. 2153-2270.

8. Commonwealth. House of Representatives. Parliamentary Debates of 24 July 1923. Official Hansard, 1923, vol. 104, pp. 1466-1516.
9. Commonwealth. House of Representatives. Parliamentary Debates of 22 March 1929. Official Hansard, 1929, vol. 120, pp. 1726-1763.

10. Commonwealth. House of Representatives. Parliamentary Debates of 3 March 1927. Official Hansard, 1927, vol. 115, pp. 56-110.

11. Commonwealth. House of Representatives. Parliamentary Debates of 25 June 1930. Official Hansard, 1930, vol. 125, pp. 3199-3265.

12. Commonwealth. House of Representatives. Parliamentary Debates of 1 August 1930. Official Hansard, 1930, vol. 12, pp. 5127-5163.

13. Conference of prime ministers and representatives of the United Kingdom, the Dominions, and India, held in June, July, and August, 1921. Session I-II. London, 1921. 68 p.

14. Evatt H. The Royal Prerogative. Law Book Co., $1987.425 \mathrm{p}$.

15. Harvey H. Consultation and Co-Operation in the Commonwealth. Oxford University Press, 1952.411 p.

16. Imperial Conference 1926. Summary of proceedings. Dublin, $1926.62 \mathrm{p}$.

17. Jonas M. Isolationism. New York, Encyclopedia of American foreign policy, 1978, vol. 2. $315 \mathrm{p}$.

18. Kennedy P. The Realities behind diplomacy: Background influences on British external policy (1865-1980). London, 1981. 416 p.

19. Mason K.J. Experience of Nationhood: Australia and the World since 1900. Sydney, McGraw Hill, 1985. 450 p.

20. McIntyre P. The Strange Death of Dominion Status. Journal of Imperial and Commonwealth History, 1999, vol. 27, no. 2, pp.193-212.

21. Meaney N. A history of Australian defence and foreign policy 1901-1923. Sydney, Sydney University Press, 2009, vol. 2. 450 p.

22. Parsons E. Wilsonian diplomacy: AlliedAmerican rivalries in war and peace. St. Louis, Forum press, $1978.213 \mathrm{p}$.

\section{Information about the Author}

Evgeniya V. Kashina, Postgraduate Student, Department of World History, Pacific National University, Tikhookeanskaya St., 136, 680035 Khabarovsk, Russian Federation, altera.pars1331@gmail.com, https:// orcid.org/0000-0003-0466-0615

\section{Информация об авторе}

Евгения Владимировна Кашина, аспирант кафедры всеобщей истории, Тихоокеанский государственный университет, ул. Тихоокеанская, 136, 680035 г. Хабаровск, Российская Федерация, altera.pars1331@gmail.com, https://orcid.org/0000-0003-0466-0615 